\title{
Risk factors for recurrent positive results of the nucleic acid amplification test for COVID-19 patients: a retrospective study
}

\author{
Wanwan $\mathrm{Yi}^{1} \cdot$ Xuan Long $^{2} \cdot$ Jin Liu $^{1} \cdot$ LiShuai Shi $^{1} \cdot$ Zichen Chen $^{6} \cdot$ Jing Yang $^{7} \cdot$ Ziyu Yang $^{4} \cdot$ Zhongwei Lv $^{1}$. \\ Hengwei Fan $^{3,5}$
}

Received: 11 May 2021 / Accepted: 16 September 2021 / Published online: 23 September 2021

(c) The Author(s) 2021

\begin{abstract}
Positive retests of COVID-19 represent a public health concern because of the increased risk of transmission. This study explored whether factors other than the nucleic acid amplification test (NAAT) contribute to positive retest results. Patients with COVID-19 admitted to the Guanggu district of the Hubei Maternal and Child Health Hospital between February 17 and March 28, 2020, were retrospectively included. The patients were grouped into the negative $(n=133)$ and positive $(n=51)$ retest groups. The results showed that the proportion of patients presenting with cough was higher $(P<0.001)$ and the proportion of patients with dyspnea was lower $(P=0.018)$ in the positive than in the negative retest group. The positive retest group showed shorter durations between symptom onset and hospitalization $(P<0.001)$ and symptom onset and the first positive NAAT $(P=0.033)$. The positive retest group had higher basophil counts $(P=0.023)$ and direct bilirubin $(P=0.032)$ and chlorine concentrations $(P=0.023)$ but lower potassium concentrations $(P=0.001)$ than the negative retest group. Multivariable regression analysis showed that coughing $(\mathrm{OR}=7.59,95 \% \mathrm{CI} 2.28-25.32, P=0.001)$ and serum chloride concentrations $(\mathrm{OR}=1.38,95 \% \mathrm{CI} 1.08-1.77, P=0.010)$ were independently associated with a positive retest result. Coughing and serum chloride concentrations were independent risk factors for positive NAAT retest results. Patients with a hospital stay of $<2$ weeks or a short incubation period should stay in isolation and be monitored to reduce transmission. These results could help identify patients who require closer surveillance.
\end{abstract}

Keywords COVID-19 $\cdot$ SARS-CoV-2 $\cdot$ Nucleic acid amplification tests $\cdot$ Positive retest $\cdot$ Negative retest

Wanwan Yi, Xuan Long and Jin Liu have contributed equally to this work.

Ziyu Yang

569440303@qq.com

$\triangle$ Zhongwei Lv

Lvzwjs2020@163.com

$\triangle$ Hengwei Fan

fanhengwei2006@163.com

1 Department of Nuclear Medicine, Shanghai Tenth People's Hospital, Tongji University School of Medicine, Yanchang Middle Road 301, Shanghai 20072, China

2 Department of Respiratory Diseases, Shanghai Tenth People's Hospital, Tongji University School of Medicine, Yanchang Middle Road 301, Shanghai 20072, China

3 Department of Hepatic Surgery, The Eastern Hepatobiliary Surgery Hospital, Navy Medical University (Second Military
Medical University), Yangpu Road 225, Shanghai 200438, China

4 Department of Integrated Chinese and Western Medicine, The Eastern Hepatobiliary Surgery Hospital, Navy Medical University (Second Military Medical University), Shanghai 200438, China

5 Department of Infection Medicine, Guanggu District, Maternal and Child Health Hospital of Hubei Province, Wuhan 430070, Hubei, China

6 Department of Standardized Training Base for Resident Physicians, Shanghai Tenth People's Hospital of Tongji University, Shanghai, China

7 Department of Chemistry and Pharmacy, Guangxi Normal University, Guangxi 541004, China 


\section{Introduction}

Coronavirus disease 2019 (COVID-19), caused by SARS$\mathrm{CoV}-2$, is extremely contagious, and it spreads rapidly globally; it had affected $>210$ million people and caused $>4.5$ million deaths as of September, 2021 [1]. The common signs of COVID-19 include fever, cough, and shortness of breath [2]. Several cases are mild, but the mortality rate is high for patients who develop the critical form of the disease [3, 4]. The infection has no recognized treatment [2-4], but vaccines may help control it [5-7].

The key to optimal COVID-19 management is the identification of positive cases. Such cases should be isolated to prevent the spreading of the disease $[8,9]$ Nevertheless, the available tests are not perfect, errors in sampling and specimen handling can occur, and a patient can have a very low viral load at sampling $[10,11]$.

There is a report of two cases of medical staff who tested positive for viral RNA during their post-discharge surveillance after clinical recovery from COVID-19 [12]. This report involved only two patients and a detailed analysis was not conducted, but it highlighted a concern for healthcare workers globally. Yin et al. [13] analyzed the clinical characteristics of 58 patients with COVID-19 who were finally diagnosed after multiple negative nucleic acid amplification test (NAAT) results, which showed that multi-site specimens could be taken to reduce the number of missed diagnoses of patients with multiple nucleic acid negatives. Moreover, no studies have focused on understanding the clinical characteristics of patients with recurrent positive NAAT results, and it is unknown whether they are false negatives that finally turn positive, recurrences, or reinfections [14-17]. A better understanding of these cases can facilitate the adjustment of the current discharge criteria, identification of patients with specific pre-existing conditions affecting retest results, and the determination of predictive factors for recurrent positive NAAT results. These points are critical for the development of epidemic control guidelines globally.

Since positive retest results for COVID-19 represent a public health concern because of the increased risk of transmission, this retrospective study comprehensively assessed 184 patients with COVID-19 grouped according to the number of times they tested positive into the negative (positive just once) and positive (positive on more than one test) retest groups. The results of this study can help identify the risk factors for positive retest results.

\section{Materials and methods}

\section{Study design and patients}

This retrospective study examined the data of patients with COVID-19 admitted and treated at the Guanggu District of the Hubei Maternal and Child Health Hospital between February 17 and March 28, 2020. The diagnostic criteria for patient classification were based on the diagnosis and treatment protocol for COVID-19 pneumonia (4th edition) [18]. The study was approved by the ethics committee of the Hubei Maternal and Child Health Hospital (\#FYGG(L)2020-004), and written informed consent was obtained from all the patients. The study was performed in adherence to the principles of the Declaration of Helsinki.

\section{Data collection}

The patients' basic information, clinical manifestations, laboratory test results, and imaging data were obtained from their electronic medical records by the attending physicians. All laboratory test results were measured during the first hospitalization. The drugs for COVID-19 patients were determined by the clinicians. There are no definitive treatments for COVID-19 patients, and the specific medications selected were adopted by clinicians based on a combination of the patient's condition and the latest guidelines at the time $[2-4,19]$. Chronic respiratory diseases include asthma, chronic obstructive pulmonary disease (COPD), bronchiectasis, and other non-acute chronic lung diseases.

\section{NAAT for SARS-CoV-2}

After treatment, the patient was discharged after two consecutive negative NAATs $[19,20]$. If a patient had a relapse of the symptoms, NAAT was repeated. At this time, the patients were re-hospitalized because of the positive NAAT; these patients were considered repeatedly positive patients. Nasopharyngeal swabs used for NAAT were collected by the professional medical staff. The samples were analyzed using the 2019-nCoV nucleic acid detection kit (fluorescence-based PCR technique) produced by Shanghai Zhijiang Biotechnology Co., Ltd. (Shanghai, China). This kit uses reverse transcription-polymerase chain reaction (RT-PCR) combined with TaqMan technology and specific primers to detect viral RNA sequences. The test results were interpreted based on the instructions by the manufacturer of the kit. For indeterminate results, the specimens were collected and tested for a second time. 


\section{Statistical analysis}

SPSS 23.0 (IBM Corp., Armonk, NY, USA) was used to conduct all statistical analyses in this study. The continuous data were presented as mean \pm standard deviation (SD). For inter-group comparisons of continuous variables, the independent $t$ test was used for normally distributed datasets and the non-parametric rank-sum test was used for non-normally distributed datasets. Discrete data were described using frequency, and the Chi-square test was used for inter-group comparisons. Univariate logistic regression was used to analyze the significantly different variables, and multivariable binary logistic regression was used to analyze the symptoms and laboratory test results that showed statistical significance during univariate logistic regression. $P<0.05$ denoted statistical significance for all two-tailed tests.

\section{Results}

\section{Characteristics of the patients}

A total of 184 COVID-19 patients were included in this study; $81(44.02 \%)$ were men. They had a mean age of $59.76 \pm 14.38$ years, mean height of $162.54 \pm 6.43 \mathrm{~cm}$, and mean weight of $62.25 \pm 10.60 \mathrm{~kg}$. The positive retest group included 51 patients $(27.71 \%)$, including 20 men (39.21\%) and 31 women $(60.78 \%)$. The negative retest group was comprised of 133 patients $(72.28 \%)$, including 61 men $(45.86 \%)$ and 72 women $(54.13 \%)$. There were no significant differences in sex, height, weight, age, number of family members, living space, or duration of exercise between the two groups $(P>0.05)$ (Table 1$)$.

\section{Comorbidities}

Of the 184 patients, $78(42.39 \%)$ had pre-existing conditions: 24 had hypertension (13.04\%), 9 had cardiovascular

Table 1 Characteristics of the patients in the positive retest group and negative retest group

\begin{tabular}{|c|c|c|c|c|}
\hline Feature & All & Negative retest group & Positive retest group & $P$ \\
\hline Age (years), mean $\pm \operatorname{SD}(n)$ & $59.76 \pm 14.38(184)$ & $60.34 \pm 14.04(133)$ & $58.24 \pm 15.25(51)$ & 0.703 \\
\hline Men, $n(\%)$ & $81(44.02 \%)$ & $61(45.86 \%)$ & $20(39.22 \%)$ & 0.416 \\
\hline Height $(\mathrm{cm})$, mean $\pm \mathrm{SD}(n)$ & $162.54 \pm 6.43(56)$ & $162.67 \pm 5.89(39)$ & $162.24 \pm 7.72(17)$ & 0.801 \\
\hline Weight $(\mathrm{kg})$, mean $\pm \mathrm{SD}(n)$ & $62.25 \pm 10.60(56)$ & $62.41 \pm 10.43(39)$ & $61.88 \pm 11.30(17)$ & 0.915 \\
\hline Number of family members, mean $\pm \mathrm{SD}(n)$ & $3.54 \pm 1.59(50)$ & $3.65 \pm 1.70(34)$ & $3.31 \pm 1.35(16)$ & 0.517 \\
\hline Housing area $\left(\mathrm{m}^{2}\right)$, mean $\pm \mathrm{SD}(n)$ & $97.98 \pm 27.71(41)$ & $94.19 \pm 24.12(26)$ & $104.53 \pm 32.90(15)$ & 0.362 \\
\hline Exercise & & & & 0.682 \\
\hline No exercise, $n(\%)$ & $18(42.86 \%)$ & $12(42.86 \%)$ & $6(42.86 \%)$ & \\
\hline$\leq 1 \mathrm{~h} /$ day, $n(\%)$ & $16(38.10 \%)$ & $12(42.86 \%)$ & $4(28.57 \%)$ & \\
\hline $1-2$ h/day, $n(\%)$ & $4(9.52 \%)$ & $2(7.14 \%)$ & $2(14.29 \%)$ & \\
\hline$\geq 2$ h/day, $n(\%)$ & $4(9.52 \%)$ & $2(7.14 \%)$ & $2(14.29 \%)$ & \\
\hline Hypertension, $n(\%)$ & $24(13.04 \%)$ & $18(13.53 \%)$ & $6(11.76 \%)$ & 0.750 \\
\hline Diabetes (type 1 and type 2 diabetes), $n(\%)$ & $8(4.35 \%)$ & $5(3.76 \%)$ & $3(5.88 \%)$ & 0.527 \\
\hline Cardiovascular disease, $n(\%)$ & $9(4.89 \%)$ & $7(5.26 \%)$ & $2(3.92 \%)$ & 0.706 \\
\hline Cerebrovascular disease, $n(\%)$ & $2(1.09 \%)$ & $1(0.75 \%)$ & $1(1.96 \%)$ & 0.479 \\
\hline Chronic respiratory disease, $n(\%)$ & $7(3.80 \%)$ & $6(4.51 \%)$ & $1(1.96 \%)$ & 0.769 \\
\hline Coexistence of 2 or more comorbidities, $n(\%)$ & $28(15.22 \%)$ & $19(14.29 \%)$ & $9(17.56 \%)$ & 0.570 \\
\hline Highest temperature $\left({ }^{\circ} \mathrm{C}\right)$, mean $\pm \mathrm{SD}(n)$ & $36.97 \pm 0.91(154)$ & $36.95 \pm 0.89(112)$ & $37.03 \pm 0.95(42)$ & 0.751 \\
\hline Heart rate $(\mathrm{bpm})$, mean $\pm \mathrm{SD}(n)$ & $84.85 \pm 12.23(172)$ & $84.58 \pm 11.45(129)$ & $85.65 \pm 14.42(43)$ & 0.880 \\
\hline Pulse oxygen saturation $(\%)$, mean $\pm \mathrm{SD}(n)$ & $97.10 \pm 2.53(49)$ & $97.30 \pm 2.21(46)$ & $94.00 \pm 5.29(3)$ & 0.122 \\
\hline The overall course (days), mean $\pm \mathrm{SD}(n)$ & $48.02 \pm 13.45(161)$ & $50.45 \pm 12.71(110)$ & $42.78 \pm 13.61(51)$ & 0.001 \\
\hline Hospitalization days, mean $\pm \operatorname{SD}(n)$ & $21.05 \pm 10.31(174)$ & $24.00 \pm 10.18(123)$ & $13.94 \pm 6.49(51)$ & $<0.001$ \\
\hline Days from onset to hospitalization, mean $\pm \mathrm{SD}(n)$ & $15.47 \pm 11.05(157)$ & $17.79 \pm 10.37(108)$ & $10.35 \pm 10.86(49)$ & $<0.001$ \\
\hline Days from onset to the first nucleic acid positive, mean $\pm \mathrm{SD}(n)$ & $17.98 \pm 16.08(91)$ & $20.81 \pm 15.14(43)$ & $15.44 \pm 16.62(48)$ & 0.033 \\
\hline $\begin{array}{l}\text { Number of negative nucleic acid tests (until the first positive), } \\
\text { mean } \pm \operatorname{SD}(n)\end{array}$ & $2.91 \pm 1.22(181)$ & $2.81 \pm 1.23(133)$ & $3.19 \pm 1.14(48)$ & 0.037 \\
\hline
\end{tabular}

The $\mathrm{n}$ in brackets represents the number of subjects with data 
disease (4.89\%), 8 had diabetes (4.35\%), 2 had cerebrovascular disease $(1.09 \%), 7$ had chronic respiratory disease (3.80\%), and 28 had two or more comorbidities (15.22\%). In the positive retest group, 22 patients had comorbidities (43.13\%): 6 had hypertension, 3 had diabetes, 2 had cardiovascular disease, 1 had cerebrovascular disease, 1 had chronic respiratory disease, and 9 had two or more comorbidities. In the negative retest group, 56 patients had preexisting conditions (42.10\%): 18 had hypertension, 5 had diabetes, 7 had cardiovascular disease, 1 had cerebrovascular disease, 6 had chronic respiratory disease, and 19 had two or more comorbidities. There were no significant differences between the two groups related to comorbidities (Table 1).

\section{Course of disease, hospital stay, and NAAT}

The average course of disease for all the patients was $48.02 \pm 13.45$ days. The overall duration of disease was $50.45 \pm 12.71$ days for the negative retest group and $42.78 \pm 13.61$ days for the positive retest group $(P=0.001)$. The sensitivity of the overall duration of the disease was $100.0 \%$; specificity was $64.70 \%$, and the likelihood ratio was 2.83 . The average durations of hospital stay were $21.05 \pm 10.31$ days for all the patients, $24.00 \pm 10.18$ days for the negative retest group, and $13.94 \pm 6.49$ days for the positive retest group $(P<0.001)$. The sensitivity of the number of days of hospitalization was $100.00 \%$; specificity was $47.10 \%$, and the likelihood ratio was 1.89 . The average duration from symptom onset to hospitalization was $15.47 \pm 11.05$ days for all patients, $17.79 \pm 10.37$ days for the negative retest group, and $10.35 \pm 10.86$ days for the positive retest group $(P<0.001)$. The sensitivity of the duration from onset to hospitalization was $50.00 \%$; specificity was $82.40 \%$ and the likelihood ratio was 2.84 . The average duration from symptom onset to the first positive NAAT result was $17.98 \pm 16.08$ days for all patients, $20.81 \pm 15.14$ days for the negative retest group, and $15.44 \pm 16.62$ days for the positive retest group $(P=0.033)$. The sensitivity of the duration from symptom onset to the first positive NAAT result was $50.00 \%$; specificity was $94.10 \%$, and the likelihood ratio was 8.47. On average, the number of negative results before the first positive result was $2.91 \pm 1.22 \%$ for all the patients, $2.81 \pm 1.23$ for the negative retest group, and $3.19 \pm 1.14$ for the positive retest group $(P=0.037)$. The sensitivity of the number of negative nucleic acid tests (until the first positive) was $0.10 \%$; the specificity was $91.7 \%$, and the likelihood ratio was 1.18 (Tables 1,2 ).

\section{Clinical signs and symptoms}

Of the 184 COVID-19 patients in this study, 113 had a fever (61.41\%), 56 had a cough (30.43\%), 98 experienced fatigue (53.26\%), 63 had muscle pain (34.24\%), 48 had dyspnea (26.09\%), and 132 had poor appetite (71.74\%). In the positive retest group, 27 patients presented with a cough (52.94\%), while 29 in the negative retest group presented with a cough $(21.80 \%)(P<0.001)$. The sensitivity of cough was $52.90 \%$; specificity was $78.20 \%$, and the likelihood ratio was 2.43 . Seven patients in the positive retest group had dyspnea (13.73\%), in contrast with 41 in the negative retest
Table 2 Sensitivity, specificity, and likelihood ratio of statistically significant variables (excluding treatment-related variables)

\begin{tabular}{lrrl}
\hline Variables & Sensitivity $(\%)$ & Specificity $(\%)$ & Likelihood ratio \\
\hline Hospitalization days & 100.00 & 47.10 & 1.89 \\
Overall course & 100.00 & 64.70 & 2.83 \\
Onset to hospitalization & 50.00 & 82.40 & 2.84 \\
Time from symptom onset to the & 50.00 & 94.10 & 8.47 \\
$\quad$ first positive NAAT result & & & \\
Number of negative nucleic acid & 0.10 & 91.70 & 1.18 \\
$\quad$ tests (until the first positive) & & & \\
Cough & 52.90 & 78.20 & 2.43 \\
Dyspnea & 86.30 & 39.80 & 1.43 \\
Ground-glass opacities & 82.40 & 40.60 & 1.39 \\
Bilateral lung infection & 5.90 & 97.00 & 1.97 \\
Inflammatory absorption & 5.90 & 98.50 & 3.93 \\
Basophilic & 50.00 & 52.90 & 1.06 \\
Total protein & 100.00 & 5.90 & 1.06 \\
Globulin & 9.10 & 96.00 & 2.28 \\
Direct bilirubin & 50.00 & 64.70 & 1.42 \\
Potassium & 50.00 & 94.10 & 8.47 \\
Chlorine & 100.00 & 0.00 & 1.00 \\
APTT & 100.00 & 23.50 & 1.31 \\
\hline
\end{tabular}


group $(30.83 \%)(P=0.018)$. The sensitivity of dyspnea was $86.30 \%$; specificity was $39.80 \%$, and the likelihood ratio was 1.43 (Tables 2, 3).

\section{Chest CT scan features}

Of the 184 patients, $65.76 \%$ had ground-glass opacities, $60.33 \%$ had bilateral lung infection, $9.23 \%$ had unilateral lung infection, and $46.74 \%$ showed inflammatory exudate absorption on their chest CT scan. In addition, $59.40 \%$ of the negative retest group and $82.35 \%$ of the positive retest group showed ground-glass opacities $(P=0.003)$. The sensitivity of ground-glass opacities was $82.40 \%$; the specificity was $40.60 \%$, and the likelihood ratio was 1.39 . Bilateral lung infection was found in $51.88 \%$ of the patients in the negative retest group and $82.35 \%$ of patients in the positive retest group $(P<0.001)$. The sensitivity of bilateral lung infection was $5.90 \%$; specificity was $97.00 \%$, and the likelihood ratio was 1.97 . In the negative retest group, $35.34 \%$ of the patients showed inflammatory exudate absorption on their CT scans, in contrast with $76.47 \%$ of the patients in the positive retest group $(P<0.001)$. The sensitivity of inflammatory exudate absorption was 5.90\%; specificity was $98.50 \%$, and the likelihood ratio was 3.93 (Tables 2, 3).

\section{Laboratory tests}

The mean basophil count was $0.03 \pm 0.02 \times 10^{9}$ cells $/ \mathrm{L}$ in the positive retest group and $0.02 \pm 0.01 \times 10^{9}$ cells $/ \mathrm{L}$ in the negative retest group $(P=0.023)$. The sensitivity of the basophil count was $50.00 \%$; specificity was $52.90 \%$, and the likelihood ratio was 1.06 . The mean serum total protein concentration was $68.73 \pm 6.01 \mathrm{~g} / \mathrm{L}$ in the negative retest group and $71.79 \pm 6.71 \mathrm{~g} / \mathrm{L}$ in the positive retest group $(P=0.014)$. The sensitivity of serum total protein concentration was $100 \%$; specificity was $5.90 \%$, and the likelihood ratio was 1.06 . The mean globulin concentration was $30.17 \pm 4.02 \mathrm{~g} / \mathrm{L}$ in the negative retest group and $32.97 \pm 4.46 \mathrm{~g} / \mathrm{L}$ in the positive retest group $(P=0.001)$. The sensitivity of the globulin concentration was $9.10 \%$; specificity was $96.00 \%$, and the likelihood ratio was 2.28 . The mean serum direct bilirubin was $4.05 \pm 1.68 \mu \mathrm{mol} / \mathrm{L}$ in the negative retest group and $5.06 \pm 2.47 \mu \mathrm{mol} / \mathrm{L}$ in the positive retest group $(P=0.032)$. The sensitivity of the direct bilirubin concentration was
Table 3 Comparison of the clinical symptoms and computed tomography imaging of lung between two groups

\begin{tabular}{|c|c|c|c|c|}
\hline Feature & Total $(n=184)$ & $\begin{array}{l}\text { Negative retest } \\
\text { group }(n=133)\end{array}$ & $\begin{array}{l}\text { Positive retest } \\
\text { group }(n=51)\end{array}$ & $P$ \\
\hline Fever, $n(\%)$ & $113(61.41)$ & $84(63.16)$ & $29(56.86)$ & 0.432 \\
\hline Cough, $n(\%)$ & $56(30.43)$ & $29(21.80)$ & $27(52.94)$ & $<0.001$ \\
\hline Hemoptysis, $n(\%)$ & $1(0.54)$ & $1(0.75)$ & $0(0.00)$ & 0.535 \\
\hline Chest tightness, $n(\%)$ & $35(19.02)$ & $23(17.29)$ & $12(23.53)$ & 0.335 \\
\hline Chest pain, $n(\%)$ & $8(4.35)$ & $6(4.51)$ & $2(3.92)$ & 0.861 \\
\hline Nasal congestion, $n(\%)$ & $1(0.54)$ & $1(0.75)$ & $0(0.00)$ & 0.535 \\
\hline Runny nose, $n(\%)$ & $1(0.54)$ & $1(0.75)$ & $0(0.00)$ & 0.535 \\
\hline Sore throat, $n(\%)$ & $9(4.89)$ & $8(6.02)$ & $1(1.96)$ & 0.254 \\
\hline Fatigue, $n(\%)$ & $98(53.26)$ & $69(51.88)$ & $29(56.86)$ & 0.544 \\
\hline Muscle aches, $n(\%)$ & $63(34.24)$ & $48(36.09)$ & $15(29.41)$ & 0.393 \\
\hline Drowsiness, $n(\%)$ & $1(0.54)$ & $1(0.75)$ & $0(0.00)$ & 0.535 \\
\hline Headache, $n(\%)$ & $5(2.72)$ & $3(2.26)$ & $2(3.92)$ & 0.534 \\
\hline Dyspnea, $n(\%)$ & 48 (26.09) & $41(30.83)$ & $7(13.73)$ & 0.018 \\
\hline Abdominal pain, $n(\%)$ & $3(1.63)$ & $2(1.50)$ & $1(1.96)$ & 0.827 \\
\hline Diarrhea, $n(\%)$ & $15(8.15)$ & $10(7.52)$ & $5(9.80)$ & 0.612 \\
\hline Nausea, $n(\%)$ & $3(1.63)$ & $1(0.75)$ & $2(3.92)$ & 0.129 \\
\hline Vomiting, $n(\%)$ & $5(2.72)$ & $2(1.50)$ & $3(5.88)$ & 0.102 \\
\hline Poor appetite, $n(\%)$ & $132(71.74)$ & $100(75.19)$ & $32(62.75)$ & 0.057 \\
\hline Ground-glass opacity, $n(\%)$ & $121(65.76)$ & $79(59.40)$ & $42(82.35)$ & 0.003 \\
\hline Consolidation, $n(\%)$ & $7(3.80)$ & $4(3.01)$ & $3(5.88)$ & 0.362 \\
\hline Mixed manifestation, $n(\%)$ & $5(2.72)$ & $2(1.50)$ & $3(5.88)$ & 0.102 \\
\hline The left lung infection, $n(\%)$ & $7(3.80)$ & $6(4.51)$ & $1(1.96)$ & 0.418 \\
\hline The right lung infection, $n(\%)$ & $10(5.43)$ & $8(6.02)$ & $2(3.92)$ & 0.575 \\
\hline Bilateral lung infection, $n(\%)$ & $111(60.33)$ & $69(51.88)$ & $42(82.35)$ & $<0.001$ \\
\hline Inflammatory absorption, $n(\%)$ & $86(46.74)$ & $47(35.34)$ & $39(76.47)$ & $<0.001$ \\
\hline
\end{tabular}


$50.00 \%$; specificity was $64.70 \%$, and the likelihood ratio was 1.42. Significant differences between the negative and positive retest groups were observed for the potassium $(4.45 \pm 0.67$ vs. $4.07 \pm 0.51 \mathrm{mmol} / \mathrm{L}, P=0.001)$ and chlorine $(104.76 \pm 2.63$ vs. $105.93 \pm 2.16 \mathrm{mmol} / \mathrm{L}, P=0.023)$ concentrations and the activated partial thromboplastin time (APTT) $(31.71 \pm 5.26$ vs. $33.26 \pm 3.86, P=0.045)$. The sensitivities of the serum potassium and chloride concentrations and the APTT were 50\%, 100\%, and 100\%, respectively. Their specificities were $94.10 \%, 0 \%$, and $23.5 \%$, and their likelihood ratios were $8.47,1$, and 1.31 , respectively (Tables 2,4 ).

Table 4 Comparison of the laboratory examinations between two groups

\begin{tabular}{|c|c|c|c|}
\hline Characteristic & The negative on retest group & The positive on retest group & $P$ \\
\hline White blood cells $\left(\times 10^{9} / \mathrm{L}\right)$, mean $\pm \mathrm{SD}(n)$ & $5.99 \pm 2.28(127)$ & $6.04 \pm 1.53(35)$ & 0.427 \\
\hline Red blood cells $\left(\times 10^{12} / \mathrm{L}\right)$, mean $\pm \operatorname{SD}(n)$ & $4.20 \pm 0.56(127)$ & $4.20 \pm 0.65(36)$ & 0.980 \\
\hline Hemoglobin $(\mathrm{g} / \mathrm{L})$, mean $\pm \mathrm{SD}(n)$ & $129.60 \pm 20.38(127)$ & $129.11 \pm 20.08(35)$ & 0.364 \\
\hline Platelets $\left(\times 10^{9} / \mathrm{L}\right)$, mean $\pm \mathrm{SD}(n)$ & $227.36 \pm 73.62(127)$ & $217.41 \pm 66.32(34)$ & 0.455 \\
\hline Neutrophil granulocytes $\left(\times 10^{9} / \mathrm{L}\right)$, mean $\pm \mathrm{SD}(n)$ & $3.83 \pm 2.19(127)$ & $3.75 \pm 1.33(33)$ & 0.614 \\
\hline Neutrophil granulocytes $(\%)$, mean $\pm \operatorname{SD}(n)$ & $61.50 \pm 11.26(127)$ & $61.42 \pm 9.84(33)$ & 0.970 \\
\hline Lymphocytes $\left(\times 10^{9} / \mathrm{L}\right)$, mean $\pm \mathrm{SD}(n)$ & $1.55 \pm 0.48(128)$ & $1.71 \pm 0.61(37)$ & 0.173 \\
\hline Lymphocytes (\%), mean $\pm \mathrm{SD}(n)$ & $27.88 \pm 8.76(128)$ & $29.39 \pm 9.36(37)$ & 0.376 \\
\hline Monocytes $\left(\times 10^{9} / \mathrm{L}\right)$, mean $\pm \operatorname{SD}(n)$ & $0.44 \pm 0.52(127)$ & $0.41 \pm 0.14(34)$ & 0.714 \\
\hline Monocytes $(\%)$, mean $\pm \mathrm{SD}(n)$ & $7.04 \pm 2.37(127)$ & $7.02 \pm 2.14(34)$ & 0.937 \\
\hline Eosnophils $\left(\times 10^{9} / \mathrm{L}\right)$, mean $\pm \mathrm{SD}(n)$ & $0.15 \pm 0.15(127)$ & $0.13 \pm 0.08(34)$ & 0.659 \\
\hline Eosnophils $(\%)$, mean \pm SD $(n)$ & $2.66 \pm 2.52(127)$ & $2.74 \pm 3.65(34)$ & 0.962 \\
\hline Basophils $\left(\times 10^{9} / \mathrm{L}\right)$, mean $\pm \mathrm{SD}(n)$ & $0.02 \pm 0.01(127)$ & $0.03 \pm 0.02(33)$ & 0.023 \\
\hline Basophils (\%), mean $\pm \mathrm{SD}(n)$ & $0.45 \pm 0.64(127)$ & $0.42 \pm 0.23(33)$ & 0.082 \\
\hline C-reactive protein $(\mathrm{mg} / \mathrm{dL})$, mean $\pm \mathrm{SD}(n)$ & $11.50 \pm 29.59(116)$ & $5.69 \pm 15.25(31)$ & 0.259 \\
\hline Fasting blood glucose $(\mathrm{mmol} / \mathrm{L})$, mean $\pm \mathrm{SD}(n)$ & $5.59 \pm 1.92(95)$ & $5.85 \pm 2.83(24)$ & 0.631 \\
\hline Serum total protein $(\mathrm{g} / \mathrm{L})$, mean $\pm \mathrm{SD}(n)$ & $68.73 \pm 6.01(108)$ & $71.79 \pm 6.71(33)$ & 0.014 \\
\hline Albumin $(\mathrm{g} / \mathrm{L})$, mean $\pm \mathrm{SD}(n)$ & $38.96 \pm 5.36(110)$ & $39.08 \pm 4.02(33)$ & 0.998 \\
\hline Globulin $(\mathrm{g} / \mathrm{L})$, mean $\pm \mathrm{SD}(n)$ & $30.17 \pm 4.02(95)$ & $32.97 \pm 4.46(32)$ & 0.001 \\
\hline Total bilirubin $(\mu \mathrm{mol} / \mathrm{L})$, mean $\pm \mathrm{SD}(n)$ & $10.23 \pm 5.21(110)$ & $11.58 \pm 5.73(32)$ & 0.260 \\
\hline Direct bilirubin $(\mu \mathrm{mol} / \mathrm{L})$, mean $\pm \operatorname{SD}(n)$ & $4.05 \pm 1.68(110)$ & $5.06 \pm 2.47(32)$ & 0.032 \\
\hline $\operatorname{ALT}(\mathrm{U} / \mathrm{L})$, mean $\pm \mathrm{SD}(n)$ & $29.65 \pm 25.68(110)$ & $27.99 \pm 30.39(33)$ & 0.395 \\
\hline $\operatorname{AST}(\mathrm{U} / \mathrm{L})$, mean $\pm \mathrm{SD}(n)$ & $21.32 \pm 12.86(110)$ & $22.92 \pm 27.44(33)$ & 0.463 \\
\hline $\operatorname{ALP}(\mathrm{U} / \mathrm{L})$, mean $\pm \mathrm{SD}(n)$ & $78.39 \pm 27.25(111)$ & $76.53 \pm 18.75(32)$ & 0.768 \\
\hline GGT $(\mathrm{U} / \mathrm{L})$, mean $\pm \mathrm{SD}(n)$ & $35.70 \pm 32.68(111)$ & $31.91 \pm 20.64(32)$ & 0.666 \\
\hline $\mathrm{TBA}(\mu \mathrm{mol} / \mathrm{L})$, mean $\pm \mathrm{SD}(n)$ & $4.82 \pm 4.30(109)$ & $3.29 \pm 2.08(31)$ & 0.053 \\
\hline Urea nitrogen $(\mathrm{mmol} / \mathrm{L})$, mean $\pm \mathrm{SD}(n)$ & $4.91 \pm 3.13(95)$ & $4.42 \pm 1.11(30)$ & 0.757 \\
\hline Creatinine $(\mu \mathrm{mol} / \mathrm{L})$, mean $\pm \mathrm{SD}(n)$ & $71.47 \pm 53.23(97)$ & $65.01 \pm 10.74(29)$ & 0.657 \\
\hline Uric acid $(\mu \mathrm{mol} / \mathrm{L})$, mean $\pm \mathrm{SD}(n)$ & $301.80 \pm 89.85(102)$ & $326.70 \pm 90.21(30)$ & 0.108 \\
\hline Potassium, mean $\pm \mathrm{SD}(n)$ & $4.45 \pm 0.67(103)$ & $4.07 \pm 0.51(30)$ & 0.001 \\
\hline Sodium, mean $\pm \operatorname{SD}(n)$ & $142.68 \pm 29.51(103)$ & $140.89 \pm 29.10(28)$ & 0.116 \\
\hline Chlorine, mean $\pm \mathrm{SD}(n)$ & $104.76 \pm 2.63(102)$ & $105.93 \pm 2.16(28)$ & 0.023 \\
\hline Calcium, mean $\pm \mathrm{SD}(n)$ & $2.16 \pm 0.19(102)$ & $2.13 \pm 0.22(29)$ & 0.947 \\
\hline Phosphorus, mean $\pm \mathrm{SD}(n)$ & $1.13 \pm 0.24(92)$ & $1.18 \pm 0.19(28)$ & 0.366 \\
\hline Prothrombin time $(\mathrm{s})$, mean $\pm \mathrm{SD}(n)$ & $11.99 \pm 1.87(98)$ & $11.45 \pm 0.88(24)$ & 0.148 \\
\hline International normalized ratio, mean $\pm \mathrm{SD}(n)$ & $1.07 \pm 0.16(98)$ & $1.05 \pm 0.08(22)$ & 0.601 \\
\hline Activated partial thromboplastin time (s), mean $\pm \mathrm{SD}(n)$ & $31.71 \pm 5.26(98)$ & $33.26 \pm 3.86(23)$ & 0.045 \\
\hline Fibrinogen $(\mathrm{g} / \mathrm{L})$, mean $\pm \mathrm{SD}(n)$ & $3.60 \pm 1.08(98)$ & $3.45 \pm 0.85(24)$ & 0.864 \\
\hline Thrombin time $(\mathrm{s})$, mean $\pm \mathrm{SD}(n)$ & $15.82 \pm 3.19(98)$ & $15.10 \pm 1.61(22)$ & 0.092 \\
\hline D-Dimer $(\mathrm{ng} / \mathrm{mL})$, mean $\pm \mathrm{SD}(n)$ & $0.94 \pm 1.55(74)$ & $0.46 \pm 0.55(22)$ & 0.255 \\
\hline
\end{tabular}

Data were displayed as mean $\pm \mathrm{SD}$

$A L T$ alanine aminotransferase, $A S T$ aspartate aminotransferase, $A L P$ alkaline phosphatase, $G G T \gamma$-glutamyl transpeptidase, $T B A$ total bile acid 


\section{Treatment}

Of the 184 patients, $71.20 \%$ were treated with Traditional Chinese Medicine (TCM). The rates of TCM decoction treatment were $55.64 \%$ for the negative retest group and $21.57 \%$ for the positive retest group $(P<0.001)$. The sensitivity of the receipt of TCM decoction treatment was $78.40 \%$; specificity was $55.60 \%$, and the likelihood ratio was 1.77 . The rate of oseltamivir phosphate usage was $25.56 \%$ for the negative retest group and $1.96 \%$ for the test-retest group $(P<0.001)$. The sensitivity of oseltamivir phosphate use was $98.00 \%$; specificity was $25.60 \%$, and the likelihood ratio was 1.32 . The average duration of use of antiviral medication by the negative retest group was $8.60 \pm 4.18$ days, compared with $4.29 \pm 4.25$ days for the positive retest group $(P<0.001)$. The mean duration of antibiotic treatment was $10.22 \pm 4.19$ days for the negative retest group and $1.87 \pm 3.90$ days for the positive retest group $(P<0.001)$. The sensitivity of the average duration of antiviral treatment and the mean course of antibiotic treatment was $100.00 \%$; specificity was $88.20 \%$, and the likelihood ratio was 8.47 . The average course of TCM in the negative on retest group was $9.79 \pm 4.83$ days, compared with $7.00 \pm 6.49$ days in the positive on retest group $(P=0.047)$. The sensitivity of the TCM course was $81.80 \%$, specificity was $56.00 \%$, and the likelihood ratio was 1.86. The rate of oxygen inhalation therapy was $77.60 \%$ in the negative retest group and $46.90 \%$ in the test-retest group $(P=0.005)$. The sensitivity of oxygen inhalation therapy was $53.10 \%$, the specificity was $77.60 \%$, and the likelihood ratio was 2.37 (Tables 5, 6).

\section{Regression analysis}

The significantly different characteristics of the two groups were analyzed using univariable logistic regression. The significant characteristics with $P<0.05$ in the univariate analyses were included in the multivariable logistic regression. Univariable regression showed that cough, dyspnea and the total protein, globulin, direct bilirubin, potassium, and chloride concentrations were all statistically correlated with a positive retest result $(P<0.001, P=0.022, P=0.017$, $P=0.002, P=0.012, P=0.003$, and $P=0.025$, respectively). Multivariable regression analysis showed that coughing $(\mathrm{OR}=7.59,95 \%$ CI $2.28-25.32, P=0.001)$ and serum chloride concentrations $(\mathrm{OR}=1.38,95 \%$ CI $1.08-1.77$,
Table 5 Comparison of treatment between the two groups

Table 6 Sensitivity, specificity and likelihood ratio of variables where the difference is statistically significant (treatment-related variables)

\begin{tabular}{llllr}
\hline Treatment & Total $(n=184)$ & $\begin{array}{l}\text { Negative on retest } \\
\text { group }(n=133)\end{array}$ & $\begin{array}{l}\text { Positive on retest } \\
\text { group }(n=51)\end{array}$ & $P$ \\
\hline Traditional Chinese medicine, $n(\%)$ & $131(71.20)$ & $97(72.93)$ & $34(66.67)$ & 0.401 \\
$\quad$ Lianhua qingwen capsules & $95(51.63)$ & $72(54.14)$ & $23(45.10)$ & 0.272 \\
Herbal decoctions & $85(46.20)$ & $74(55.64)$ & $11(21.57)$ & $<0.001$ \\
Anti-viral therapy, $n(\%)$ & $113(61.41)$ & $86(64.66)$ & $27(52.94)$ & 0.144 \\
Abidor & $62(33.70)$ & $44(33.08)$ & $18(35.29)$ & 0.776 \\
Oseltamivir phosphate capsules & $35(19.02)$ & $34(25.56)$ & $1(1.96)$ & $<0.001$ \\
Antibiotics, $n(\%)$ & $51(27.72)$ & $36(27.07)$ & $15(29.41)$ & 0.751 \\
Moxifloxacin & $49(26.63)$ & $36(27.07)$ & $13(25.49)$ & 0.828 \\
Azithromycin & $1(0.54)$ & $0(0.00)$ & $1(1.96)$ & 0.105 \\
Meropenem & $1(0.54)$ & $1(0.75)$ & $0(0.00)$ & 0.535 \\
Days of drugs (d), mean \pm SD & & & & 0.047 \\
Days of taking Chinese medicine & $8.63 \pm 5.71$ & $9.79 \pm 4.83$ & $7.00 \pm 6.49$ & $<0.001$ \\
Days of antiviral drugs & $6.80 \pm 4.70$ & $8.60 \pm 4.18$ & $4.29 \pm 4.25$ & $<0.001$ \\
Days of antibiotics & $6.41 \pm 5.81$ & $10.22 \pm 4.19$ & $1.87 \pm 3.90$ & 0.005 \\
Oxygen inhalation, $n(\%)$ & $53.0(65.40)$ & $38.0(77.60)$ & $15.0(46.90)$ & \\
\hline
\end{tabular}

\begin{tabular}{lcll}
\hline Variables & Sensitivity $(\%)$ & Specificity $(\%)$ & Likelihood ratio \\
\hline Course of antiviral treatment & 100.00 & 88.20 & 8.47 \\
Course of antibiotic treatment & 100.00 & 88.20 & 8.47 \\
TCM decoction treatment & 78.40 & 55.60 & 1.77 \\
Oseltamivir phosphate use & 98.00 & 25.60 & 1.32 \\
Course of TCM & 81.80 & 56.00 & 1.86 \\
Oxygen inhalation therapy & 53.10 & 77.60 & 2.37 \\
\hline
\end{tabular}


$P=0.010$ ) were independently associated with recurrent positive NAAT results (Table 7).

\section{Discussion}

Reports of COVID-19 patients retesting positive on NAAT have drawn significant attention [14-17, 20]. This study explored whether factors other than NAAT contribute to positive retest results. The characteristics of 184 COVID-19 patients were retrospectively analyzed. There was no significant difference in gender between the two groups, which was consistent with the findings of Wan et al. [21]. The mean age of the patients was 59.76 years, and $58.20 \%$ were $>60$ years old. This is consistent with the study by Yang et al. [22], who postulated that older people aged $\geq 60$ years are more susceptible to infection by SARS-CoV-2 and its associated mortality. Moreover, more than half of the patients had preexisting conditions, including hypertension, diabetes, cardiovascular disease, and chronic respiratory disease. The incidence of COVID-19 is higher among patients with multiple comorbidities. This finding is consistent with the results reported by Zhou et al. [23]. They reported that $48 \%$ of the 191 patients enrolled in their study had pre-existing conditions, with the most common being hypertension, diabetes, and coronary heart diseases [23].

The Chinese Diagnosis and Treatment Protocol for COVID-19 Pneumonia (8th edition) states that the incubation period for COVID-19 is generally 3-7 days and can be up to 14 days. This study showed that the average duration of disease in the 184 patients was 48.02 days; the average hospital stay was 21.05 days, and the average duration from symptom onset to the first positive NAAT result was 17.98 days. These results confirmed that COVID-19 had a slow onset, a prolonged duration, and a long incubation period. The predictive model from Lauer et al. [24] estimates that 101 of every 10,000 cases will develop symptoms of COVID-19 after 14 days of isolation. This conclusion is consistent with the results of this study, which demonstrated that the average duration from symptom onset to the first positive NAAT result was $17.98 \pm 16.08$ days for all patients, $20.81 \pm 15.14$ days for the negative retest group, and $15.44 \pm 16.62$ days for the positive retest group. The duration from symptom onset to hospitalization and the duration from the onset of symptoms to the first positive NAAT result were shorter for the positive retest group than for the negative retest group, indicating that patients in the positive retest group had a shorter incubation period and a rapid disease progression.

The average duration of hospital stay of the patients in the positive retest group was only 13.94 days, which was significantly shorter than that of the patients in the negative retest group (24.00 days). This is consistent with the significantly lower patronage of TCM, oseltamivir, antiviral medications, herbal decoctions, and other drugs in the positive retest group than in the negative retest group. We speculated that the patients in the positive retest group were not adequately treated and could still transmit the virus, leading to a positive NAAT retest. Therefore, we recommend that patients with a hospital stay duration of $<2$ weeks should stay in isolation after discharge and be monitored to reduce transmission.

The current discharge criteria for COVID-19 patients in China are two consecutive negative NAAT results from respiratory specimens with at least 1 day between the two samplings. However, in this study, 184 patients underwent 2.91 NAATs before the first positive result; the number of NAATs in the negative retest group was 2.81, and the average number of NAATs in the positive retest group was
Table 7 Univariate and multivariable logistic regression analysis of independent risk factors for recurrent positive NAAT results

\begin{tabular}{|c|c|c|c|c|c|c|}
\hline \multirow[t]{2}{*}{ Variable } & \multicolumn{3}{|c|}{ Univariate analysis } & \multicolumn{3}{|c|}{ Multivariable analysis } \\
\hline & $\overline{\mathrm{OR}}$ & $95 \% \mathrm{CI}$ & $P$ & $\overline{\mathrm{OR}}$ & $95 \% \mathrm{CI}$ & $P$ \\
\hline Cough & 0.248 & $0.125-0.493$ & $<0.001$ & 7.594 & $2.278-25.322$ & 0.001 \\
\hline Dyspnea & 0.357 & $0.148-0.859$ & 0.022 & 0.541 & $0.116-2.515$ & 0.433 \\
\hline Basophilic $\left(\times 10^{9} / \mathrm{L}\right)$ & 1.270 & $0.991-1.626$ & 0.059 & & & \\
\hline Total protein $(\mathrm{g} / \mathrm{L})$ & 1.086 & $1.015-1.162$ & 0.017 & 1.056 & $0.936-1.191$ & 0.377 \\
\hline Globulin (g/L) & 1.168 & $1.057-1.290$ & 0.002 & 1.054 & $0.897-1.237$ & 0.524 \\
\hline Direct bilirubin $(\mu \mathrm{mol} / \mathrm{L})$ & 1.284 & $1.056-1.560$ & 0.012 & 1.295 & $0.960-1.747$ & 0.091 \\
\hline Potassium (mmol/L) & 0.278 & $0.120-0.644$ & 0.003 & 0.487 & $0.162-1.462$ & 0.199 \\
\hline Chlorine (mmol/L) & 1.766 & $1.074-2.901$ & 0.025 & 1.382 & $1.082-1.766$ & 0.010 \\
\hline $\begin{array}{l}\text { Activated partial thrombo- } \\
\text { plastin time (s) }\end{array}$ & 1.052 & $0.970-1.141$ & 0.219 & & & \\
\hline
\end{tabular}

Univariate logistic regression was performed on significantly different variables, and multivariable binary logistic regression was performed on symptoms and laboratory tests that showed statistical significance in the univariate logistic regression $(P<0.05)$

OR odds ratio, $95 \%$ CI $95 \%$ confidence interval 
3.19. To better control the spread of the disease, hospitals should ensure that the discharge criteria are strictly followed, and we recommend obtaining at least three negative NAAT results before discharging a patient combined with the significant relief of clinical symptoms, the significant improvement of ground-glass changes on chest $\mathrm{CT}$, and the significant resolution of inflammation.

The common symptoms of COVID-19 include fever, shortness of breath, fatigue, and dyspnea [2, 25]. The results of this study showed that $61.43 \%$ of the participants had fever, $30.43 \%$ experienced coughing, $53.26 \%$ experienced fatigue, $34.24 \%$ experienced muscle pain, $26.09 \%$ experienced dyspnea, and $71.74 \%$ had poor appetite. The proportion of patients who presented with cough was significantly higher in the positive retest group than in the negative retest group, which may be attributed to the higher SARS-CoV-2 viral load in the positive retest group. Imaging features are of great significance for the diagnosis of COVID-19 [26-28]. The positive retest group showed a higher incidence of bilateral lung infection and ground-glass opacities than the negative retest group. Therefore, COVID-19 patients with bilateral lung infections, ground-glass lesions, and other imaging manifestations should be aware of the possibility of recurrence, and nucleic acid monitoring should be strengthened for them.

Increases in the basophil count are mainly observed in patients with allergies and blood and some infectious diseases, including influenza, smallpox, and tuberculosis [29-31]. Shen et al. [32] found significantly increased basophil counts in patients with H1N1 influenza. In the present study, the basophil count was higher in the positive retest group. The basophil count is easily affected by factors such as the detection instrument, temperature of the environment, and the ratio of anticoagulants and can show a false increase. After eliminating the various confounding factors and the allergic condition, if a patient shows high basophil counts on reexamination under the microscope, there is a high possibility that this patient will have a positive result on retest for viral RNA after being discharged, and the basophil count should be followed up closely during the post-discharge isolation. The concentrations of serum globulin and direct bilirubin were both higher for the positive retest group, implying that patients in the positive retest group had more severe liver damage. The actual condition of the patients needs to be evaluated to determine whether hepatoprotective drugs should be prescribed during treatment for COVID-19.

The electrolytes in human plasma play a decisive role in maintaining the osmotic pressure of extracellular fluids, acid-base balance, and the distribution and transfer of body fluids. Changes in the concentrations of electrolytes cause electrolyte disorders $[33,34]$. Abnormal concentrations of potassium and chlorine can cause organ damage and even death [35-37]. SARS-CoV-2 binds to angiotensin-converting enzyme 2 (ACE2), which is its receptor, reduces ACE2 expression, and increases angiotensin II, which can result in increased renal reabsorption of chlorine and potassium excretion and, ultimately, high chloride and low potassium concentrations [38-41]. Our research shows that the chlorine concentrations of patients in the positive retest group were increased, and the regression analysis also indicated that the chloride concentrations help predict the risk of positive retest results. The serum potassium concentrations were significantly lower in the positive retest group. This result further indicated that the virus load in the positive group was higher than that in the negative group. Therefore, COVID19 patients with electrolyte disturbances should be closely followed up. We also recommend stricter discharge criteria and increased NAAT testing for these patients.

This study offers some valuable insights into COVID19, but it has some limitations. First, the specimens used for NAAT were obtained using nasopharyngeal swabs, and the detection rates for viral RNA from these types of specimens are still under evaluation. Hase et al. [42] reported a case where the induced sputum specimen tested positive on NAAT while the throat swab collected on the same day tested negative. Factors such as the type of specimen and the part of the body the specimen is collected from may be important causes of positive retests. Second, this was a retrospective study with some missing data, which may have led to inevitable biases. For example, there were extreme data on the number of days of hospitalization, overall course, and the concentrations of total protein and chlorine, with a sensitivity of $100.0 \%$. Chlorine had a specificity of $0.0 \%$, which implies that some data can only be used as limited references.

\section{Conclusion}

There were several differences in the clinical characteristics, laboratory test results, imaging features, and treatment outcomes of the patients in the negative and positive retest groups. These differences are highly predictive of retest outcomes and may be useful for guiding risk assessment and clinical management, especially cough and blood chloride concentrations, according to the multivariable analysis. In addition, our results suggested that patients with a hospital stay duration of $<2$ weeks or a short incubation period should stay in isolation and be monitored after discharge to reduce transmission.

Acknowledgements The authors would like to thank Dr. Xiaohui Fu (the Eastern Hepatobiliary Surgery Hospital) for the critical revision of this article.

Funding This work was supported by the Fundamental Research Funds for the Central Universities (\#22120180392 and \#15012150066), the 
Shanghai Tenth People's Hospital (\#2021SYPDRC065), the Shanghai Science and Technology Commission Support Plan (\#18441903500), the Shanghai Leading Talent program sponsored by Shanghai Human Resources and Social Security Bureau (\#03.05.19005), the Guanggu District of Hubei Province Maternal and Child Health Hospital (\#2020FYGG-021), the key discipline construction project of the three-year action plan of Shanghai public health system (\#GWV-10.1-XK9) and the Shanghai Municipal Health Commission (\#202040043 and \#20214Y0159).

\section{Declarations}

Conflict of interest The authors declare that they have no conflicts of interest.

Ethical approval The study was approved by the ethics committee of the Hubei Maternal and Child Health Hospital (\#FYGG(L)2020-004).

Informed consent Written informed consent was obtained from all the patients.

Open Access This article is licensed under a Creative Commons Attribution 4.0 International License, which permits use, sharing, adaptation, distribution and reproduction in any medium or format, as long as you give appropriate credit to the original author(s) and the source, provide a link to the Creative Commons licence, and indicate if changes were made. The images or other third party material in this article are included in the article's Creative Commons licence, unless indicated otherwise in a credit line to the material. If material is not included in the article's Creative Commons licence and your intended use is not permitted by statutory regulation or exceeds the permitted use, you will need to obtain permission directly from the copyright holder. To view a copy of this licence, visit http://creativecommons.org/licenses/by/4.0/.

\section{References}

1. WHO Coronavirus (COVID-19) Dashboard. [Updated 2021]. https://covid19. who.int/. Cited 3 Sep 2021.

2. Wiersinga WJ, Rhodes A, Cheng AC, Peacock SJ, Prescott HC. Pathophysiology, transmission, diagnosis, and treatment of coronavirus disease 2019 (COVID-19): a review. JAMA. 2020;324:782-93.

3. Gandhi RT, Lynch JB, Del Rio C. Mild or moderate COVID-19. N Engl J Med. 2020;383:1757-66.

4. Esakandari H, Nabi-Afjadi M, Fakkari-Afjadi J, Farahmandian N, Miresmaeili SM, Bahreini E. A comprehensive review of COVID-19 characteristics. Biol Proced Online. 2020;22:19.

5. Heaton PM. The COVID-19 vaccine-development multiverse. N Engl J Med. 2020;383:1986-8.

6. Dal-Ré R, Caplan AL, Gluud C, Porcher R. Ethical and scientific considerations regarding the early approval and deployment of a COVID-19 vaccine. Ann Intern Med. 2021;174:258-60.

7. Locht C. Vaccines against COVID-19. Anaesth Crit Care Pain Med. 2020;39:703-5.

8. Zhai Q, Hu C, Luo C. Multi-plate reconstruction for severe bicondylar tibial plateau fractures of young adults. Int Orthop. 2014;38:1031-5.

9. Yu B, Han K, Zhan C, Zhang C, Ma H, Su J. Fibular head osteotomy: a new approach for the treatment of lateral or posterolateral tibial plateau fractures. Knee. 2010;17:313-8.
10. Kucirka LM, Lauer SA, Laeyendecker O, Boon D, Lessler J. Variation in false-negative rate of reverse transcriptase polymerase chain reaction-based SARS-CoV-2 tests by time since exposure. Ann Intern Med. 2020;173:262-7.

11. Ji T, Liu Z, Wang G, et al. Detection of COVID-19: a review of the current literature and future perspectives. Biosens Bioelectron. 2020;166:112455.

12. Xing Y, Mo P, Xiao Y, Zhao O, Zhang Y, Wang F. Post-discharge surveillance and positive virus detection in two medical staff recovered from coronavirus disease 2019 (COVID-19), China, January-February 2020. Eurosurveillance. 2020; 25.

13. Yin J, Liu $\mathrm{C}, \mathrm{Wu} \mathrm{X}$. Clinical characteristics of patients with multiple negative RNA tests but diagnosed with COVID-19. Chin J Nosocomiol. 2020;30:801-5.

14. Xiao AT, Tong YX, Zhang S. False negative of RT-PCR and prolonged nucleic acid conversion in COVID-19: rather than recurrence. J Med Virol. 2020;92:1755-6.

15. Dao TL, Hoang VT, Gautret P. Recurrence of SARS-CoV-2 viral RNA in recovered COVID-19 patients: a narrative review. Eur J Clin Microbiol Infect Dis. 2021;40:13-25.

16. Hoang VT, Dao TL, Gautret P. Recurrence of positive SARSCoV-2 in patients recovered from COVID-19. J Med Virol. 2020;92:2366-7.

17. Osman AA, Al Daajani MM, Alsahafi AJ. Re-positive coronavirus disease 2019 PCR test: could it be a reinfection? New microbes and new infections. 2020;37:100748.

18. Lobenhoffer P, Gerich T, Bertram T, Lattermann C, Pohlemann T, Tscheme H. Particular posteromedial and posterolateral approaches for the treatment of tibial head fractures. Unfallchirurg. 1997;100:957-67.

19. Jeffcoate WJ, Price P, Harding KG, International Working Group on Wound H, Treatments for People with Diabetic Foot $\mathrm{U}$. Wound healing and treatments for people with diabetic foot ulcers. Diabetes Metab Res Rev. 2004;20(Suppl 1):S78-89.

20. Chen D, Xu W, Lei Z, et al. Recurrence of positive SARSCoV-2 RNA in COVID-19: a case report. Int J Infect Dis IJID. 2020;93:297-9.

21. Wan S, Xiang Y, Fang W, et al. Clinical features and treatment of COVID-19 patients in northeast Chongqing. J Med Virol. 2020;92:797-806.

22. Yang L, Liu J, Zhang R, et al. Epidemiological and clinical features of 200 hospitalized patients with corona virus disease 2019 outside Wuhan, China: a descriptive study. J Clin Virol. 2020;129:104475.

23. Zhou F, Yu T, Du R, et al. Clinical course and risk factors for mortality of adult inpatients with COVID-19 in Wuhan, China: a retrospective cohort study. Lancet (Lond Engl). 2020;395:1054-62.

24. Lauer SA, Grantz KH, Bi Q, et al. The incubation period of coronavirus disease 2019 (COVID-19) from publicly reported confirmed cases: estimation and application. Ann Intern Med. 2020;172:577-82.

25. Du Y, Tu L, Zhu P, et al. Clinical features of 85 fatal cases of COVID-19 from Wuhan. A retrospective observational study. Am J Respir Crit Care Med. 2020;201:1372-9.

26. Meng H, Xiong R, He R, et al. CT imaging and clinical course of asymptomatic cases with COVID-19 pneumonia at admission in Wuhan China. J Infect. 2020;81:e33-9.

27. Zhao W, Zhong Z, Xie X, Yu Q, Liu J. CT scans of patients with 2019 novel coronavirus (COVID-19) pneumonia. Theranostics. 2020;10:4606-13.

28. Liang T, Liu Z, Wu CC, et al. Evolution of CT findings in patients with mild COVID-19 pneumonia. Eur Radiol. 2020;30:4865-73. 
29. García-Ródenas MDM, Fernández-Aracil C, Marco-de-la-Calle FM. Might basophils be a reliable biomarker in severe asthma? Arch Bronconeumol. 2021;57:79-80.

30. Shameli A, Jamani K. Acute promyelocytic leukemia presenting with atypical basophils. Clin Case Rep. 2020;8:584-5.

31. Nagao M, Fujisawa T, Ihara T, Kino Y. Highly increased levels of $\operatorname{IgE}$ antibodies to vaccine components in children with influenza vaccine-associated anaphylaxis. J Allergy Clin Immunol. 2016;137:861-7.

32. Shen H, Li B, Bai B, et al. Laboratory features throughout the disease course of influenza A (H1N1) virus infection. Clin Lab. 2013;59:337-42.

33. Seifter JL. Integration of acid-base and electrolyte disorders. $\mathrm{N}$ Engl J Med. 2014;371:1821-31.

34. Palmer BF, Clegg DJ. Electrolyte disturbances in patients with chronic alcohol-use disorder. N Engl J Med. 2017;377:1368-77.

35. Núñez J, Bayés-Genís A, Zannad F, et al. Long-term potassium monitoring and dynamics in heart failure and risk of mortality. Circulation. 2018;137:1320-30.

36. Seifter JL. Body fluid compartments, cell membrane ion transport, electrolyte concentrations, and acid-base balance. Semin Nephrol. 2019;39:368-79.

37. Polcwiartek C, Hansen SM, Kragholm K, et al. Prognostic role of serum sodium levels across different serum potassium levels in heart failure patients: a Danish register-based cohort study. Int J Cardiol. 2018;272:244-9.

38. Chen D, Li X, Song Q, et al. Assessment of hypokalemia and clinical characteristics in patients with coronavirus disease 2019 in Wenzhou China. JAMA Netw Open. 2020;3:e2011122.

39. Liu Y, Yang Y, Zhang C, et al. Clinical and biochemical indexes from 2019-nCoV infected patients linked to viral loads and lung injury. Sci China Life Sci. 2020;63:364-74.

40. Lippi G, South AM, Henry BM. Electrolyte imbalances in patients with severe coronavirus disease 2019 (COVID-19). Ann Clin Biochem. 2020;57:262-5.

41. Hall JE, do Carmo JM, da Silva AA, Wang Z, Hall ME. Obesity, kidney dysfunction and hypertension: mechanistic links. Nat Rev Nephrol. 2019;15:367-85.

42. Hase R, Kurita T, Muranaka E, Sasazawa H, Mito H, Yano Y. A case of imported COVID-19 diagnosed by PCR-positive lower respiratory specimen but with PCR-negative throat swabs. Infect Dis (Lond, Engl). 2020;52:423-6.

Publisher's Note Springer Nature remains neutral with regard to jurisdictional claims in published maps and institutional affiliations. 